\author{
Military Technical College \\ Kobry El-Kobbah, \\ Cairo, Egypt
}

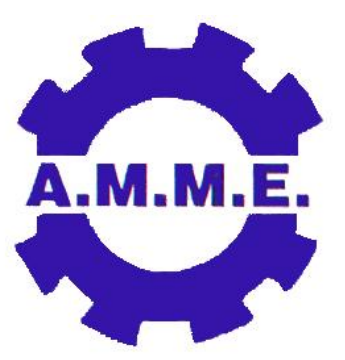

$14^{\text {th }}$ International Conference on Applied Mechanics and Mechanical Engineering.

\title{
BALLISTIC RESISTANCE OF SINGLE AND MULTI-LAYERED METALLIC TARGETS
}

\author{
By \\ M.A. Abdel-Wahed ${ }^{*}$, A.M. Riad* ${ }^{*}$ A.M. Salem and A.S. Zidan*
}

\begin{abstract}
Normal penetration of armor-piercing projectiles into single and multi-layered steel targets has been investigated. An experimental program has been conducted to study the ballistic resistance of single as well as spaced and in-contact layered targets. Armor piercing projectiles, $7.62 \mathrm{~mm}$ in caliber were used. Projectile impact velocities ranged from 300 to $600 \mathrm{~m} / \mathrm{s}$, whereas the total thicknesses of the tested single, spaced and in-contact layered steel targets were $3 \mathrm{~mm}$. The penetration process of different tested target configurations has been simulated using Autodayn-2D hydrocode. In addition, the data of projectiles and the different tested targets were fed into the analytical model developed by Liaghat et al. [1], who studied the penetration of conical projectiles into multi-layered metallic targets.
\end{abstract}

The experimental measurements of the present work were used to discuss the effect of impact velocity, target configuration and number of layers of different spaced and incontact layered steel targets on their ballistic resistance. In addition, post-firing examination of the tested targets over the used impact velocity range showed that the single and each layer of spaced and in-contact laminated steel targets failed by petalling. Finally, the obtained experimental measurements were compared with the corresponding predicted results of Autodyn-2D hydrocode and the analytical model of Ref. [1], respectively; good agreement was generally obtained.

KEY WORDS: penetration, multi-layered targets, ballistic resistance, terminal ballistics, dynamic plasticity, and numerical simulation. 


\section{* Egyptian Armed Forces. INTRODUCTION}

The penetration phenomenon of a projectile into single and multi-layered targets is of interest in many applications. Backman and Goldsmith [2] and Zukas [3] have reviewed studies which deal with experiments, analytical models and nuermical simulations for determining the ballistic limit of different target configurations and the residual velocity of projectiles for impact velocities greater than the balistic limit.

Efforts have been recently directed towards developing analytical models and software packages to predict/simulate the response of single and multi-layered targets subjected to penetration. The analytical models are based on energy balance and/or momentum conservation along with certain simplifying assumptions [4-6], whereas the developed software packages investigate the ballistic penetration of different target configurations using piecewise (finite element) or pointwise (finite difference) techniques [7-8].

The benefits of using multi-layered metallic targets compared to single targets of equal thickness are not clear yet. Almohandes et al. [9] studied experimentally the effect of target configuration on its ballistic performance when impacted by $7.62 \mathrm{~mm}$ standard bullets of different velocities. First, single steel plates, 1-8 mm thick, were tested, and the effects of thickness and mechanical properties of plate material were explored. Second, in-contact and spaced layers comprising $8 \mathrm{~mm}$-thick steel targets were tested and the effects of number, thickness, and arrangement of layers were sought. They found that: (a) The monolithic steel targets were more effective than in-contact and spaced layered targets of the same total thickness, (b) The difference in effectiveness diminished with increasing impact velocity, and (c) Resistance of laminated steel targets increased as the number of layers decreased and the thickness of the back plate increased.

Dey et al. [10] investigated experimentally and numerically the ballstic perforation resistance of double-layered steel plates impacted by blunt and ogival nosed projectiles. In their tests, $12 \mathrm{~mm}$-thick (monolithic or layered) targets of Weldox $700 \mathrm{E}$ were impacted by $20 \mathrm{~mm}$ projectiles at sub-ordnance velocities. The ballistic limits of different target combinations were determined. In addition, they also simulated the penetration process of the tested target combinations by different projectiles using Ls-Dyna code. They found that: (a) The predicted ballistic limit of each target combination was in good agreement with that determined by experiment, and (b) A large ballistic limit was offered by doublelayered systems when impacted by blunt projectiles.

Gupta and Madhu [11] investigated experimentally the normal and oblique impact of armour-piercing projectiles into single and layered plates made of mild steel, Rolled Homogenous Armor (RHA) and aluminum, respectively. Their projectiles were fired with impact velocities in the range of $800-880 \mathrm{~m} / \mathrm{s}$. Their plate thickness varied in the range of 4.7-40 $\mathrm{mm}$ and the ratio of the plate thickness to the projectile diameter varied in the range of $0.75-6.5$ for single plates and up to 13 for layered plates. Their experimental measurements showed that the single plates were more effective than the in-contact layered targets, which, in turn, were more effective than the spaced layered targets. They also derived a simple relation that could predict the target thickness capable of stopping their used projectile. 
Yossifon et al. [12] developed an analytical model for penetration of multi-layered targets by rigid projectiles using the single layer model described in Ref. [13]. Their analytical solution was developed for which the momentum equation was satisfied pointwise in the target region, while the boundary and continuity conditions were satisfied only approximately. They also assumed a single particular velocity field for all target layers. They focused on two cases of multi-layered targets: one consisting of materials which differed only by their hardnesses; and the other consisting of signifcantly different materials (RHA and Aluminium). The predictions of their analytical model were in good agreement with those of Autodyn-2D hydrocode for both cases, independently of whether the hard layer was first or second.

Woodward and Cimpoeru [14] studied the perforation of in-contact layered aluminum alloy plates, which had a variety of configurations, by flat-ended and conical nosed projectiles. They determined the ballistic limits of their tested layered plates and used the results to evaluate energy absorption mechanisms due to deformation and failure modes. They observed that the propensity to stretch and bend or to shear a plug was affected by the thickness of exit-side layer relative to the projectile diameter; plugging by shear mechanism was accompanied with thick exit-side layer. They developed an analytical model treating the perforation of layered plates in a two-stage process. These were indentation on the impact side followed by plug shear for thick exit-side layer or dishing for thin exit-side layer. The model predicts the ballistic limits of their tested targets for both flat-ended and conical nosed projectiles. They concluded that the monolithic plates were equally or more effective than the laminates.

Liang et al. [15] developed an analytical model for prdicting the ballistic performance of multi-layered targets, based on the concepts of momentum conservation, impulsemomentum equation and energy balance. Experimental measurements of Almohandes et al. [9] were used to validate the predictions of their model. For impact velocities ranging from $700-800 \mathrm{~m} / \mathrm{s}$ and a projectile aspect ratio of 4.2 , good agreement was generally obtained between their predicted residual velocities and the corresponding experimental measurements of Ref. [9]. They also found that the ballistic performance was best for the double-layered target when the ratio of the first layer thickness to the total thickness was about 0.75 and the worst performance occured when this ratio was 0.5 . Myungsoo et al. [16] also studied numerically the optimization of multi-layered targets under ballistic impact using NET2D finite element code. They concluded that the target resistance increased with increasing thickness of first layer in multi-layered targets.

This paper is concerned with experimentally investigating the effect of impact velocity, target configurations and number of layers on the ballsitic resistance of different multilayered steel targets compared with a monolithic target of equal total thickness. Moreover, comparisons of predicted results of Autodyn-2D hydrocode and the analytical model of Ref. [1], respectively, with experimental measurements confined to plates exhibiting petalling failure are performed.

\section{EXPERIMENTAL WORK}

An experimental program has been conducted to study the normal perforation of $7.62 \times 39$ $\mathrm{mm}$ armor-piercing projectile into different configurations of spaced and in-contact multilayered steel targets as well as single targets of equal thickness. In general, the scheme of the experimental work includes the following activities: (a) characterization of the used 
steel plates for preparing the single and multi-layered steel targets, (b) ballistic tests and measurements, and (c) post-firing examinations.

\section{Characterization of the Used Steel Plates}

Characterization of the steel plates was only concerned with the determination of their mechanical properties. Tensile tests were performed to determine the stress-strain behavior of the different thicknesses of steel plates. Standard tensile test specimens were prepared from steel plates of 1, 1.5, 2 and $3 \mathrm{~mm}$ thickness. Three tensile test specimens were prepared for each plate thickness.

Tests were carried out using the tensile testing machine, Model MTS-810 with a capacity of $100 \mathrm{kN}$, at a loading rate of $50 \mathrm{~N} / \mathrm{sec}$. The stress-strain behavior for each specimen was obtained. Then values of the yield and ultimate tensile strengths as well as strain to fracture were obtained.

\section{Ballistic Tests and Measurements}

Ballistic tests were performed in order to determine the projectile impact and postperforation velocities for the different targets tested. The ballistic experiments were performed in a ballistic shooing range, which had provisions for the measurement of projectile impact and post-perforation velocities, respectively. As shown in Fig. 1, the ballistic set-up consists mainly of: ballistic rifle, impact velocity and post-perforation velocity frames with their respective electronic measuring instruments, and target mount.

7.62 x $39 \mathrm{~mm}$ armor-piercing projectiles having different impact velocities ranging from 300 to $600 \mathrm{~m} / \mathrm{s}$ were fired against each target. The change in propellant charge mass was used to vary the projectile impact velocity. For each charge mass, a minimum of two shots were considered, with their average representing the projectile impact velocity. In addition, the average of the corresponding measured residual velocities was evaluated and taken as the projectile residual velocity.

Tested plates with dimensions of $200 \mathrm{~mm} \times 200 \mathrm{~mm}$ were prepared. To avoid the influence of plate boundaries on the perforation process, projectiles were fired at the effective area of each target surface which was far from its boundaries. The distance between two perforations on the same target surface was $60 \mathrm{~mm}$ at least. Each target was perforated by a maximum of 4 shots. Symbols and digits are used to designate the tested targets. For example, $3 \mathrm{~mm}$ single represents a monolithic target with total thickness of 3 $\mathrm{mm}$. In addition, $1 \mathrm{~mm}+2 \mathrm{~mm}$ represents an in-contact double-layered steel target, consisting of $1 \mathrm{~mm}$-thick steel plate backed by $2 \mathrm{~mm}$-thick steel plate, whereas a $1 \mathrm{~mm}+$ $5 \mathrm{~S}+2 \mathrm{~mm}$ respresents the same double-layered steel target with $5 \mathrm{~mm}$ space between its layers.

\section{Post-Firing Examinations}

These were mainly concerned with the arrangement and the configurations of the set up, the projectile, and the target elements after perforation. After each firing test, the test setup was examined to be sure that no connections were damaged by projectile or fragments. Examining the recovered projectile after perforation of each tested target was very important in order to determine the degree of its deformation. This depended mainly on total thickness of the tested target and projectile impact velocity. For each tested single 
or multi-layered steel target, the petals height and number as well as the perforation diameter of projectile into each plate were measured. All interesting features related to target failure mode and projectiles were photographed for the analysis of test results.

\section{NUMERICAL SIMULATION}

In the following, the experimental measurements of the ballistic tests were used to confirm the validity of the Autodyn-2D hydrocode predictions. Autodyn-2D hydrocode was used to simulate the perforation process due to the impact of the $7.62 \times 39 \mathrm{~mm}$ armor-piercing projectile into each steel target configuration at each impact velocity considered.

\section{Penetrator Simulation}

The projectile used consists of a penetrator and a jacket. The penetrator is made of high strength steel with a yield stress of $1500 \mathrm{MPa}$; it also has a diameter of $6.24 \mathrm{~mm}$, a length of $23.8 \mathrm{~mm}$ and an ogival nose with a height of $9 \mathrm{~mm}$. In Autodyn-2D hydrocode, the penetrator was simulated to investigate its perforation process into the different steel targets considered. The input data of the penetrator material to the hydrocode are listed in Table 1. The equation of state was selected to be linear, whereas no erosion model was selected. In addition, Johnson-Cook equation was selected to represent the strength model for penetrator material [17].

\section{Target Plate Simulation}

The dimensions and material properties of each plate thickness used in the experimental program are fed into the hydrocode. These data are also listed in Table 1. For the material of each plate thickness, linear equation of state and erosion model of incremental geometric strain were selected. Johnson-Cook model was also selected to be a strength model of each plate thickness.

Figure 2 shows the simulated penetrator against spaced and in-contact triple-layered steel targets. The main procedure for simulating the penetrator and target into the Autodyn-2D hydrocode is [17]: (i) select suitable subgrids for penetrator and target, (b) choose Lagrange processor, (c) zone the meshing $(x, y)$ and map them by $(I, J)$, (d) fill these meshes with its respective material data listed in Table 1, (e) set the initial conditions, ( $f$ ) set the respective impact velocity of penetrator, (g) select the time step, (h) select a cycle limit and (i) run to initiate the execution of the perforation process.

\section{ANALYTICAL MODEL}

The analytical model developed by Liaghat et al. [1] is used herein to predict the parameters associated with penetration of a small caliber projectile into single, spaced and in-contact multi-layered steel targets failing by petalling. The selected model can calculate the energy required for the deformation of each layer and petalling formation; this energy includes plastic, dynamic and bending portions. The main assumptions and equations representing the analytical model are presented in Ref. [18]. These equations are arranged and compiled into a computer program.

The input data to the model are: (i) projectile diameter, mass, apex angle of its tip and impact velocity, and (ii) thickness, density and yield strength of each layer material contributing to the target, in addition to the number of layers and their arrangement. The model is capable of predicting the ballistic limit, residual velocity and total time of projectile 
penetration into single and multi-layered metallic targets. In the present work, the model predictions are only concerned with projectile velocity after perforating the single or multilayered steel target at each measured impact velocity.

\section{RESULTS AND DISCUSSIONS}

The present results are divided into: (i) results of plate material characterization, (ii) ballistic firing test results, (iii) post-firing examinations of targets and recovered penetrators, and (iv) comparisons between experimental measurements and the corresponding predicted results of Autodyn-2D hydrocode and the analytical model of Ref. [1], respectively.

\section{Results of Plate Material Characterization}

The stress-strain curves obtained for the different specimen thicknesses show that the values of strain to failure, yield strength and the tensile strength are close. In addition, the relation between tensile stress and strain is non linear for each thickness of the tested specimens. Table 1 lists the average yied stress of the tested plate thciknesses. The modulus of elasticity for each thickness of tested plates was deduced from its stress-strain behavior. The average values of elasticity modulus for the tested plate thicknesses are also listed in Table 1.

\section{Results of Ballistic Firing Tests}

The ballistic test results due to the impact of single and different multi-layered steel targets, with total thickness of $3 \mathrm{~mm}$, by small caliber penetrators having different impact velocities are presented. Both the penetrator residual velocity $\left(\mathrm{V}_{\mathrm{r}}\right)$, and velocity drop ratio $\left(D V / V_{i}\right.$, where $D V=V_{i}-V_{r}$ and $V_{i}$ is the impact velocity) are chosen to represent target ballistic resistance to penetration.

In the following, samples of the ballistic test results are presented. Figure 3 depicts the change of penetrator residual velocity with impact velocity for single, spaced and incontact triple-layered steel targets, having total thickness of $3 \mathrm{~mm}$. The figure shows that the residual velocity increases with increasing impact velocity for each target configuration. In addition, the plotted results show that the ballistic resistance of the single target is greater than that of the spaced and in-contact triple-layered target configurations, except for $\mathrm{Vi}>450 \mathrm{~m} / \mathrm{s}$, where the ballistic resistance of the in-contact triple-layered steel target is slightly greater than that of the single target. The increase of space between the triple-layered steel targets decreases their ballistic resistance. This may be attributed to the small thickness of the individual penetrated layers and the absence of support offered by backing layer during the penetration of each layer.

Figure 4 plots the change of penetrator residual velocity with impact velocity for the single, $(2 \times 1.5 \mathrm{~mm})$ spaced and in-contact double-layered steel targets, having total thickness of $3 \mathrm{~mm}$. For each target configuration, similar trends to those depicted in Fig. 3 are generally obtained. Moreover, the plotted results show that the ballistic resistance of single and spaced double-layered steel targets is greater than that of the in-contact double-layered steel target. This may be attributed to the ability of individual layers to dissipate more energy when they are spaced. This effect diminishes, however, at higher impact velocities. 
Table 1. Input data of penetrator and each thickness of plate material to Autodyn-2D hydrocode.

\begin{tabular}{|c|c|c|c|c|c|}
\hline \multirow[t]{2}{*}{ Parameter } & \multirow[t]{2}{*}{ Penetrator } & \multicolumn{4}{|c|}{$\begin{array}{c}\text { Plate material } \\
\text { thickness, }[\mathrm{mm}]\end{array}$} \\
\hline & & 1 & 1.5 & 2 & 3 \\
\hline - Reference density, $\left(\mathrm{g} / \mathrm{cm}^{3}\right)$ & 7.87 & \multicolumn{4}{|c|}{7.81} \\
\hline - Reference temperature, (K) & 300 & \multicolumn{4}{|c|}{300} \\
\hline - Penetrator length, $(\mathrm{mm})$ & 23.8 & \multicolumn{4}{|c|}{-} \\
\hline - Penetrator diameter, (mm) & 6.24 & \multicolumn{4}{|c|}{-} \\
\hline $\begin{array}{l}\text { - Plate surface dimensions, } \\
\left(\mathrm{mm}^{2}\right)\end{array}$ & - & \multicolumn{4}{|c|}{$200 \mathrm{~mm} \times 200 \mathrm{~mm}$} \\
\hline - Specific heat (C.V.), (J/kg.K) & 475 & \multicolumn{4}{|c|}{448} \\
\hline - Shear modulus, (GPa) & 80 & \multicolumn{4}{|c|}{80} \\
\hline - Yield stress (MPa) & 1500 & \multicolumn{4}{|c|}{305} \\
\hline - Elasticity modulus, (GPa) & 220 & \multicolumn{4}{|c|}{201} \\
\hline - Strain rate constant & 0.014 & \multicolumn{4}{|c|}{0.022} \\
\hline - Melting temperature, $(\mathrm{K})$ & 1537 & \multicolumn{4}{|c|}{1537} \\
\hline - Erosion strain & - & \multicolumn{4}{|c|}{1.0} \\
\hline
\end{tabular}

Figure 5 plots the change of penetrator residual velocity with impact velocity for the single, $(2 \mathrm{~mm}+1 \mathrm{~mm})$ spaced and in-contact double-layered steel targets, having total thickness of $3 \mathrm{~mm}$. The plotted results show that the ballistic resistance of the single target is greater than that of the in-contact and spaced double-layered targets, respectively. In addition, the ballistic resistance of the in-contact double-layered target is greater than that of the spaced double-layered target over the used impact velocity range. This may be explained by the influence of the backing layer in supporting the front layer of the in-contact steel target during its penetration. On the other hand, the backing layer is easily penetrated in the spaced double-layered steel target with low energy dissipation due to its small thickness.

It can be concluded from the previous figures that the differences among between the ballistic resistances of different double- and triple-layered steel target configurations diminish at high impact velocity. This conclusion is similar to that obtained by Almohandes et al. [9], who studied experimentally the effect of steel target configurations on their ballistic performance when impacted by $7.62 \mathrm{~mm}$ standard bullets of different velocities.

Figure 6 plots the change of projectile velocity drop ratio $\left(D V / V_{i}\right)$ with impact velocity for single, spaced and in-contact triple-layered steel targets having total thickness of $3 \mathrm{~mm}$. For each target configuration, it is seen from the figure that the velocity drop ratio always decreases with increasing impact velocity. The present figure also shows that the penetrator velocity drop ratio during its penetration to the in-contact triple-layered target is greater than that of the single target of equal total thickness for $V_{i}>450 \mathrm{~m} / \mathrm{s}$. In addition, the spaced triple-layered targets have lower effect on penetrtor velocity drop ratio in comparison with that of single and in-contact triple-layered targets of equal total thickness. 
Figure 7 depicts the change of projectile velocity drop ratio with impact velocity for single, spaced and in-contact double-layered steel targets of equal total thickness. Similar trends to those plotted in Fig. 6 for the change of velocity drop ratio as function of imapct velocity are obtained for the different single and double-layered target configurations. The present figure also shows that the single target has the greatest ballistic resistance in comparison with that of other double-layered steel target configurations. In addition, the ballistic resistance of the in-contact $(2 \mathrm{~mm}+1 \mathrm{~mm})$ steel target is greater than that of the in-contact and spaced $(1 \mathrm{~mm}+2 \mathrm{~mm})$ steel targets. This is due to the great loss of penetrator energy through the thickest layer encountering the penetrator at first. This result is similar to that obtaind by Gupta and Madhu [11] who studied experimentally the normal and oblique impact of armour-piercing projectiles into single and layered plates made of different metallic materials at velocities in the range of $800-880 \mathrm{~m} / \mathrm{s}$. The ballistic resistance of spaced $(1 \mathrm{~mm}+2 \mathrm{~mm})$ steel target in comparison with that of other double-layered target configurations does not depict consistent trend and further investigation is needed.

Figure 8 plots the change of penetrator residual velocity as function of target thickness ratio at average impact velocities of 350,448 and $558 \mathrm{~m} / \mathrm{s}$, respectively, for single and different configurations of spaced and in-contact double-layered steel targets, with total thickness of $3 \mathrm{~mm}$. The present figure shows that the ballistic resistance of single target is slightly greater than that of other double-layered steel target configurations. In addition, the present figure determines the thickness ratio of the double-layered steel targets that give maximum ballistic resistance; this thickness ratio is found to be 0.5 for the spaced double-layered target at $V_{i}=350,448$ and $558 \mathrm{~m} / \mathrm{s}$, respectively.

Figure 9 depicts the change of velocity drop ratio as function of target thickness ratio at the average impact velocities used, respectively, for single and different configurations of spaced and in-contact double-layered steel targets, with total thickness of $3 \mathrm{~mm}$. The present figure confirms that the thickness ratio of 0.5 for the spaced double-layered target gives the highest ballistic resistance compared with that of other double-layered target configurations at the respective impact velocities.

Figure 10 plots the change of velocity drop ratio with number of target layers for in-contact and spaced double $(2 \times 1.5 \mathrm{~mm})$ and triple $(3 \times 1 \mathrm{~mm})$ layered steel targets having the same total thickness at different impact velocities. The change of velocity drop ratio for the single-layered target is plotted on the same figure. For each impact velocity, the present figure shows that the single target has the highest ballistic resistance compared with that of other double- and triple-layered target configurations. In addition, the ballistic resistance of the spaced double-layered target is greater than that of the spaced and in-contact triplelayered targets except for $V_{i}=558 \mathrm{~m} / \mathrm{s}$, where the resistance of the in-contact triplelayered target is slightly greater than that of the spaced and in-contact double-layered targets.

Figure 11 plots the change of velocity drop ratio with number of target layers for single, incontact and spaced double $(1 \mathrm{~mm}+2 \mathrm{~mm})$ and triple $(3 \times 1 \mathrm{~mm})$ layered steel targets, having the same total thickness at different impact velocities. For each impact velocity, similar results to those presented in Fig. 10 for the ballistic resistance of single target in comparison with that of other double and triple-layered target configurations are obtained. In addition, the present figure shows that the ballistic resistance of the in-contact triplelayered target is greater than that of the spaced and in-contact double-layered targets at each impact velocity. Figure 12 also plots the change of velocity drop ratio with number of target layers for single, in-contact and spaced double- $(2 \mathrm{~mm}+1 \mathrm{~mm})$ and triple- $(3 \times 1 \mathrm{~mm})$ 
layered steel targets at the same average impact velocities. Similar results to those presented in Fig. 11 for the ballistic resistances of different steel target configurations are obtained.

It can be concluded from the previous figures that the single target has the highest ballistic resistance compared with that of other double and triple-layered target configurations. The spaced double-layered steel target with thickness ratio $\left(t_{1} / t_{1}+t_{2}\right)$ of 0.5 gives the highest ballistic resistance compared with that of other in-contact double-layered targets as well as the spaced and in-contact triple-layered targets at $V_{i}=350$ and $480 \mathrm{~m} / \mathrm{s}$, respectively. In addition, the ballistic resistance of the in-contact triple-layered steel target is greater than that of the different double-layered steel target configurations at $V_{i}=558 \mathrm{~m} / \mathrm{s}$. This conclusion is that the resistance is highly dependent on impact velocity, which suggests that the mechanism of failure is also velocity-dependent.

\section{Results of Post-Firing Examinations}

The recovered penetrators after perforating the single and different multi-layered steel target configurations over the used impact velocity range were examined. The perforating penetrators were not subjected to deformation (rigid) during each penetration process.

The visual inspection of single and each layer of different multi-layered steel target configurations after terminating the penetration process showed that the petalling failure mode was dominated. The number of petals ranged from five to six, as shown in Fig. 13 for the exit side of the backing layer of a double-layered steel target with $5 \mathrm{~mm}$ spacing at $V_{i}=350 \mathrm{~m} / \mathrm{s}$ and in Fig. 14 for the exit side of the backing layer of an in-contact triplelayered steel target at $V_{i}=448 \mathrm{~m} / \mathrm{s}$. The average petal heights of the perforated layers of each target configuration ranged from 4-5 mm. Moreover, the average of entrance and exit diameters ranged from 7-9 $\mathrm{mm}$ and from $8-11 \mathrm{~mm}$, respectively.

\section{Comparison among Measured Results, Corresponding Predictions of Autodyn-2D Hydrocode and those of the Analytical Model of Ref. [1]}

In the following, the experimental measurements obtained due to the perforation of different tested steel targets by small caliber penetrators at different impact velocities are compared with the predicted results of both Autodyn-2D hydrocode and analytical model of Ref. [1], respectively. Moreover, the absolute relative differences between the experimental measurements and the corresponding predicted results of Autodyn-2D, $\left(\Delta \mathrm{V}_{\mathrm{r}}\right)_{1}$, and the analytical model, $\left(\Delta \mathrm{V}_{\mathrm{r}}\right)_{2}$, are calculated. Both the analytical model and Autodyn-2D hydrocode are run to predict the penetrator residual velocities after perforating the single and different spaced and in-contact multi-layered steel targets, with total thickness of $3 \mathrm{~mm}$. Penetrator data as well as the data of each tested single or multilayered steel target fed to the hydrocode and the analytical model, respectively, are listed in Table 1.

The ballistic test results and the corresponding predictions of Autodyn-2D code and the analytical model due to the impact of single and multi-layered steel targets by small caliber penetrators having different impact velocities are listed in Table 2 . In addition, the absolute relative difference between each measurement and the corresponding predictions of Autodyn-2D code and analytical model, respectively, are listed in the same table. It is seen from the table that the maximum absolute relative difference between the measured residual velocity and the corresponding prediction of Autodyn-2D hydrocode, $\left(\Delta \mathrm{V}_{\mathrm{r}}\right)_{1}$, is $5.15 \%$ when the penetrator impacts the single target at $V_{i}=341 \mathrm{~m} / \mathrm{s}$. In addition, the 
maximum absolute relative difference between the measured residual velocity and the corresponding prediction of the analytical model, $\left(\Delta \mathrm{V}_{\mathrm{r}}\right)_{2}$, is $5.95 \%$ when the penetrator impacts the same single target at the same impact velocity.

Table 2. Comparison among ballistic test results, corresponding predictions of Autodyn-2D hydrocode and those of the analytical model of Ref. [1].

\begin{tabular}{|c|c|c|c|c|c|c|c|c|}
\hline \multicolumn{3}{|c|}{ Measured results } & \multicolumn{2}{|c|}{$\begin{array}{l}\text { Autodyn-2D } \\
\text { predictions }\end{array}$} & \multicolumn{2}{|c|}{$\begin{array}{c}\text { Predictions of } \\
\text { analytical model } \\
{[1]}\end{array}$} & \multirow{2}{*}{$\begin{array}{c}\text { Abs. } \\
\text { relative } \\
\text { differ. } \\
\left(\Delta \mathbf{V}_{r}\right)_{1}^{*} \\
{[\%]}\end{array}$} & \multirow{2}{*}{$\begin{array}{c}\text { Abs. } \\
\text { relative } \\
\text { differ., } \\
\left(\Delta \mathbf{V}_{r_{2}}\right)^{\star *} \\
{[\%]}\end{array}$} \\
\hline $\begin{array}{c}\text { Impact } \\
\text { velocity, } \\
V_{i}[\mathrm{~m} / \mathrm{s}]\end{array}$ & $\begin{array}{l}\text { Residual } \\
\text { velocity, } \\
V_{\mathrm{r}}[\mathrm{m} / \mathrm{s}]\end{array}$ & $\begin{array}{c}\text { Velocity } \\
\text { drop, } \\
\text { DV } \\
{[\mathrm{m} / \mathrm{s}]}\end{array}$ & $\begin{array}{l}\text { Residual } \\
\text { velocity, } \\
\mathrm{V}_{\mathrm{r}}[\mathrm{m} / \mathrm{s}]\end{array}$ & $\begin{array}{c}\text { Velocity } \\
\text { drop, } \\
\text { DV } \\
{[\mathrm{m} / \mathrm{s}]}\end{array}$ & $\begin{array}{l}\text { Residual } \\
\text { velocity, } \\
V_{r}[\mathrm{~m} / \mathrm{s}]\end{array}$ & \begin{tabular}{|} 
Velocity \\
drop, \\
DV \\
[m/s]
\end{tabular} & & \\
\hline \multicolumn{9}{|c|}{$3 \mathrm{~mm}$ Single } \\
\hline 341 & 252 & 89 & 265 & 76 & 267 & 74 & 5.15 & 5.95 \\
\hline 347 & 260 & 87 & 271 & 76 & 274 & 73 & 4.23 & 5.38 \\
\hline 450 & 380 & 70 & 390 & 60 & 393 & 57 & 2.63 & 3.42 \\
\hline 552 & 497 & 55 & 501 & 51 & 496 & 56 & 0.81 & 0.20 \\
\hline \multicolumn{9}{|c|}{$(1 \mathrm{~mm}+1 \mathrm{~mm}+1 \mathrm{~mm})$} \\
\hline 350 & 272 & 78 & 269 & 81 & 284 & 66 & 1.1 & 4.41 \\
\hline 450 & 380 & 70 & 380 & 70 & 395 & 55 & 0.0 & 3.95 \\
\hline 552 & 489 & 54 & 498 & 54 & 504 & 48 & 1.84 & 3.07 \\
\hline \multicolumn{9}{|c|}{$(1 \mathrm{~mm}+5 S+1 \mathrm{~mm}+5 S+1 \mathrm{~mm})$} \\
\hline 334 & 284 & 50 & 287 & 47 & 291 & 43 & 1.06 & 2.46 \\
\hline 437 & 381 & 56 & 387 & 50 & 389 & 48 & 1.57 & 2.10 \\
\hline 552 & 499 & 53 & 504 & 48 & 508 & 44 & 1.00 & 1.80 \\
\hline \multicolumn{9}{|c|}{$(1 \mathrm{~mm}+10 \mathrm{~S}+1 \mathrm{~mm}+10 \mathrm{~S}+1 \mathrm{~mm})$} \\
\hline 350 & 293 & 57 & 300 & 50 & 305 & 45 & 2.38 & 4.09 \\
\hline 450 & 405 & 45 & 400 & 50 & 409 & 41 & 1.23 & 0.98 \\
\hline 554 & 509 & 45 & 506 & 48 & 510 & 44 & 0.59 & 0.20 \\
\hline \multicolumn{9}{|c|}{$(1.5 \mathrm{~mm}+1.5 \mathrm{~mm})$} \\
\hline 345 & 268 & 77 & 262 & 73 & 265 & 80 & 2.24 & 1.12 \\
\hline 385 & 320 & 65 & 323 & 62 & 330 & 55 & 0.93 & 3.13 \\
\hline 447 & 394 & 53 & 389 & 58 & 398 & 49 & 1.27 & 1.02 \\
\hline 489 & 436 & 53 & 438 & 53 & 440 & 49 & 0.46 & 0.92 \\
\hline \multicolumn{9}{|c|}{$(1.5 \mathrm{~mm}+5 \mathrm{~S}+1.5 \mathrm{~mm})$} \\
\hline 335 & 257 & 78 & 265 & 70 & 269 & 66 & 3.11 & 4.67 \\
\hline 449 & 377 & 72 & 385 & 64 & 389 & 60 & 2.12 & 3.18 \\
\hline 553 & 502 & 51 & 505 & 48 & 506.5 & 55 & 0.59 & 0.89 \\
\hline \multicolumn{9}{|c|}{$(1.5 \mathrm{~mm}+10 \mathrm{~S}+1.5 \mathrm{~mm})$} \\
\hline 349 & 278 & 71 & 282 & 67 & 288 & 61 & 1.44 & 3.60 \\
\hline 451 & 381 & 70 & 386 & 65 & 393 & 58 & 1.31 & 3.14 \\
\hline 564 & 515 & 49 & 516 & 48 & 517 & 47 & 0.19 & 0.39 \\
\hline \multicolumn{9}{|c|}{$(1 \mathrm{~mm}+2 \mathrm{~mm})$} \\
\hline 348 & 270 & 78 & 266 & 82 & 282 & 66 & 1.48 & 4.44 \\
\hline 439 & 380 & 59 & 372 & 67 & 388 & 51 & 2.11 & 2.11 \\
\hline 552 & 507 & 45 & 501 & 51 & 500 & 52 & 1.18 & 1.38 \\
\hline
\end{tabular}




\begin{tabular}{|c|c|c|c|c|c|c|c|c|}
\hline 349 & 274 & 75 & 276 & 73 & 286 & 63 & 0.73 & 4.38 \\
\hline 449 & 379 & 70 & 381 & 68 & 390 & 59 & 0.53 & 2.90 \\
\hline 556 & 505 & 51 & 505 & 51 & 508 & 48 & 0.0 & 0.59 \\
\hline \multicolumn{9}{|c|}{$(2 \mathrm{~mm}+1 \mathrm{~mm})$} \\
\hline 351 & 270 & 81 & 270 & 81 & 283 & 68 & 0.0 & 4.81 \\
\hline 447 & 385 & 62 & 378 & 69 & 395 & 52 & 1.82 & 2.59 \\
\hline 567 & 517 & 50 & 515 & 52 & 518 & 49 & 0.39 & 0.19 \\
\hline \multicolumn{9}{|c|}{$(2 \mathrm{~mm}+5 \mathrm{~S}+1 \mathrm{~mm})$} \\
\hline 350 & 279 & 71 & 279 & 71 & 291 & 59 & 0.0 & 4.3 \\
\hline 446 & 390 & 56 & 393 & 53 & 399 & 47 & 2.31 & 2.31 \\
\hline 558 & 506 & 52 & 506 & 52 & 510 & 48 & 0.0 & 0.79 \\
\hline
\end{tabular}

${ }^{*}\left(\Delta \mathrm{V}_{\mathrm{r}}\right)_{1}=\left(\mathrm{V}_{\mathrm{r} \text { measured }}-\mathrm{V}_{\mathrm{r} \text { Autodyn }}\right) / \mathrm{V}_{\mathrm{r} \text { measured }}$, and ${ }^{* *}\left(\Delta \mathrm{V}_{\mathrm{r}}\right)_{2}=\left(\mathrm{V}_{\mathrm{r} \text { measured }}-\mathrm{V}_{\mathrm{r} \text { model }}\right) / \mathrm{V}_{\mathrm{r} \text { measured }}$

Figure 15 shows the predicted change of projectile residual velocity with impact velocity obtained by Autodyn-2D hydrocode and analytical model for single and in-contact triplelayered steel targets, respectively. For each target configuration, the measured residual velocities corresponding to different impact velocities are also depicted on the same figure. Good agreement is generally found between measured and predicted residual velocities obtained by Autodyn-2D and the analytical model over the used impact velocity range.

Figure 16 also plots the measured and the corresponding predicted change of projectile residual velocity with impact velocity for single and spaced double-layered steel targets, respectively. Good agreement is generally found between measured and predicted residual velocities obtained by Autodyn-2D and the analytical model over the used range of impact velocity. The obtained predictions prove the suitability of both Autodyn-2D hydrocode and the analytical model of Ref. [1] to use as tools for constructing single, spaced or in-contact multi-layered steel targets capable of defeating a certain small caliber threat.

\section{CONCLUSIONS}

The following points could be drawn as conclusions of the present work:

(i) The ballistic resistance of a single steel target is greater than that of in-contact and spaced double and triple-layered steel targets of equal total thickness over the used impact velocity range, except for $\mathrm{Vi}=558 \mathrm{~m} / \mathrm{s}$, where the in-contact triple-layered target has the highest ballistic resistance.

(ii) The difference between the ballistic resistance of different double and triple-layered target configurations diminishs at high impact velocity.

(iii) The spaced double-layered steel target with a thickness ratio of 0.5 (two layers of eual thickness) gives the highest ballistic resistance compared with that of other in-contact double-layered targets as well as the spaced and in-contact triple-layered targets at $\mathrm{Vi}$ $=350$ and $480 \mathrm{~m} / \mathrm{s}$, respectively. In addition, the ballistic resistance of the in-contact triple-layered steel target is greater than that of the different double-layered steel target configurations at $\mathrm{V}_{\mathrm{i}}=558 \mathrm{~m} / \mathrm{s}$. Further experimentation is needed to thoroughly investigate the reasons of such trends.

(iv) Good agreement is generally obtained between measured and predicted residual velocities of both Autdyn-2D hydrocode and the analytical model of Ref. [1] over the 
used range of impact velocity for single and different double- and triple-layered steel target configurations.

(v) Both Autodyn-2D hydrocode and the analytical model of Ref. [1] can be used as tools for constructing the single, spaced or in-contact multi-layered steel targets capable of defeating a certain small caliber threat.

\section{REFERENCES}

1. G.H. Liaghat, H.M. Naeimi and S. Felli,"The Mechanics of Normal and Oblique Penetration of Conical Projectiles into Multi-Layered Metallic Targets", Iranian J. of Sci. and Tech., Trans. B, Engineering, Vol. 29, pp. 241-251 (2005).

2. M.E. Backman and W. Goldsmith, "The Mechanics of Penetration of Projectiles into Targets", Int. J. Eng. Sci., Vol. 16, pp. 1-99 (1978).

3. A.J. Zukas, "Impact Dynamics", John Wiely \& Sons, New York, Ch. 5, pp. 157-210 (1982).

4. R.L. Woodward and M.E. De Morton, "Penetration of Targets by Flat Ended Projectiles", Int. J. Mech Sci., Vol. 8, pp. 119-127 (1976).

5. M. Ravid and S.R. Bodner, "Dynamic Perforation of Viscoplastic Plates by Rigid Projectiles" Int. J. Eng. Sci., Vol. 21, No. 6, pp. 577-591 (1983).

6. J. Liss, W. Goldsmith and J.M. Kelly, "A Phnomonological Penetration Model of Plates", Int. J. Impact Engng., Vol. 1, pp. 321-341 (1983).

7. A. Arias, J.A. Rodriguez and A. Rusinek, "Numerical Simulations of Impact Behaviour of Thin Steel Plates Subjected to Cylindrical, Conical and Hemispherical Non-Deformable Projectiles", J. Engng. Fracture Mech., Vol. 75, pp. 1635-1656 (2008).

8. T. Borvik, O.S. Hopperstad, M. Langseth and K.A. Malo,"Effect of Target thickness in Blunt Projectile Penetration of Weldex 470E Steel Plates", Int. J. Impact Engng., Vol. 28, pp. 413-464 (2003).

9. A.A. Almohandes, M.S. Abdel-Kader and A.M. Eleiche, "Experimental Investigation of the Ballistic Resistance of Steel-Fiberglass Reinforced Polyester Laminated Plates", Elsevier Science Limited, Part B, pp. 447-458 (1996).

10. S. Dey, T. Borvik and X.Teng, "On the Ballistic Resistance of Double-Layered Steel Plates: An Experimental and Numerical Investigation", Int. J. Solids and Structures, Vol. 44, pp. 6701-6723 (2007).

11. N.K.Gupta and V. Madhu, "An Experimental Study of Normal and Oblique Impact of Hard-Core Projectile on Single and Multi-Layered Plates", Int. J. Impact Engng., Vol. 19, pp. 395-414 (1997).

12. G. Yossifon, A.L.Yarin and M.B.Rubin, "Penetration of a Rigid Projectile into a MultiLayered Target: Theory and Numerical Computations", Int. J. Eng. Sci., Vol. 40, pp. 1381-1401 (2002).

13 A.L. Yarin, M.B. Rubin and I.V. Roisman, "Penetration of a Rigid Projectile into an Elastic-Plastic Targets of Finite Thicknesses", Int. J. Impact Engng., Vol. 16, pp.801831 (1995).

14 R.L.Woodward and S.J. Cimpoeru, "A Study of the Perforation of Aluminum Laminate Targets", Int. J. Impact Engng., Vol. 21, pp. 117-131 (1998).

15. C. Liang, M. Yang, P. Wu and T. Teng, "Resistant Performance of Perforation of Multi-Layered Target Using an Estimation Procedure with Marine Application", Ocean Engng., Vol. 32, pp. 441-468 (2004).

16. P. Myungsoo, J. Yoo and D.T. Chung, "An Optimization of a Multi-Layered Target Under Ballistic Impact", Int. J. Solids and Struct., Vol. 42, pp. 123-137 (2005).

17. "AUTODYN Theory Manual", Revision 3.0, Century Dynamics Inc. (1997). 
18. M.A. Abdel-Wahed, "Penetration of Multi-layered targets by Small Caliber Projectiles", M. Sc. Dissertation, M.T.C. (in preparation, 2010).

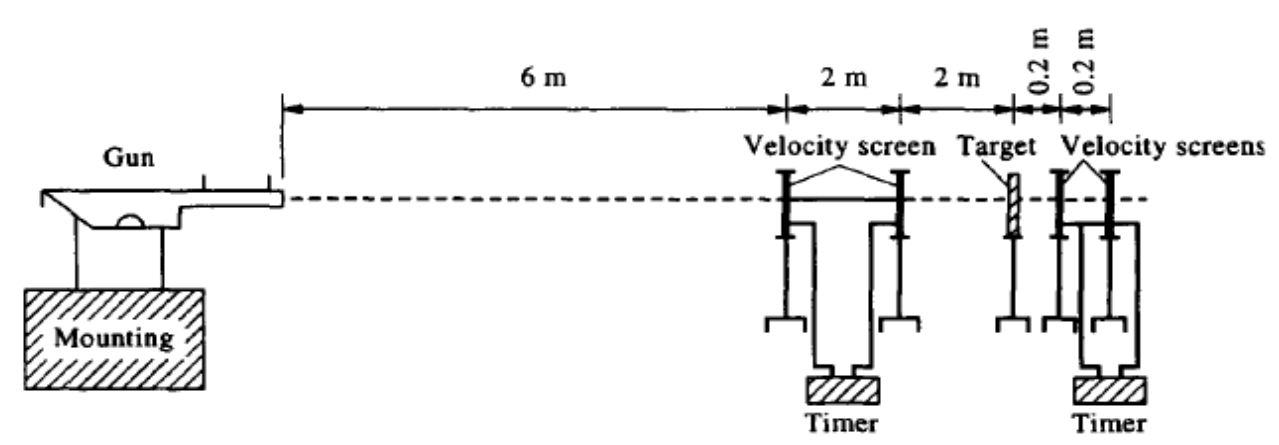

Fig.1. A scheme of ballistic test steup.

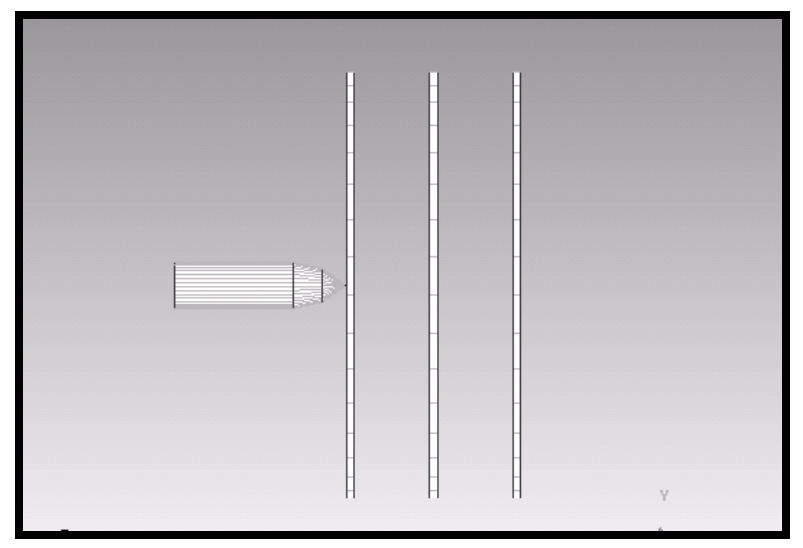

(a)

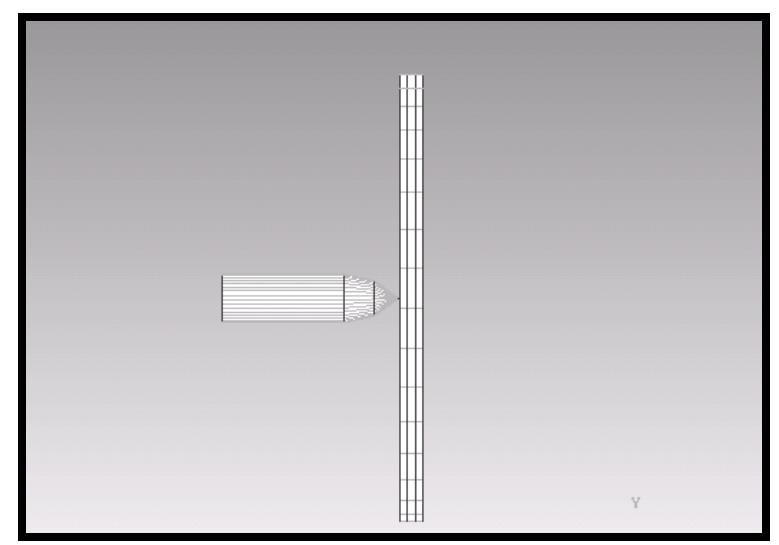

(b)

Fig. 2. Simulation of hard steel penetrator against triple-layered steel targets, (a) spaced and (b) in-contact.

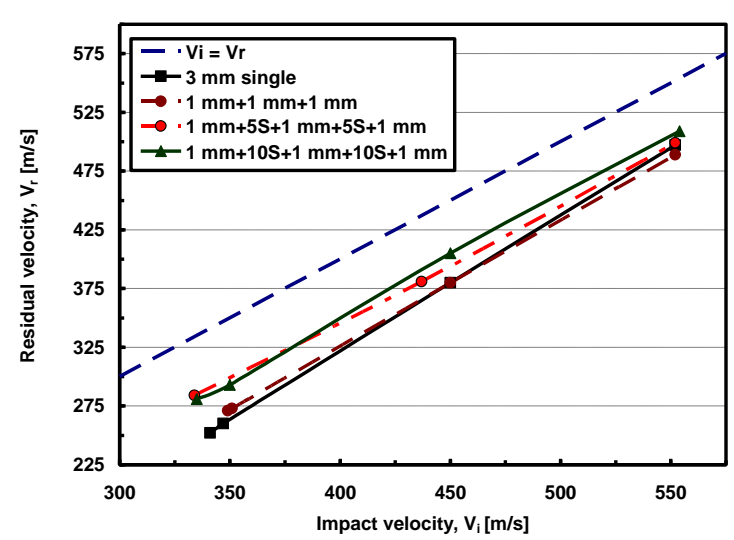

Fig. 3. Change of residual velocity with impact velocity for single, in-contact and spaced triple-layered targets having the same total thickness.

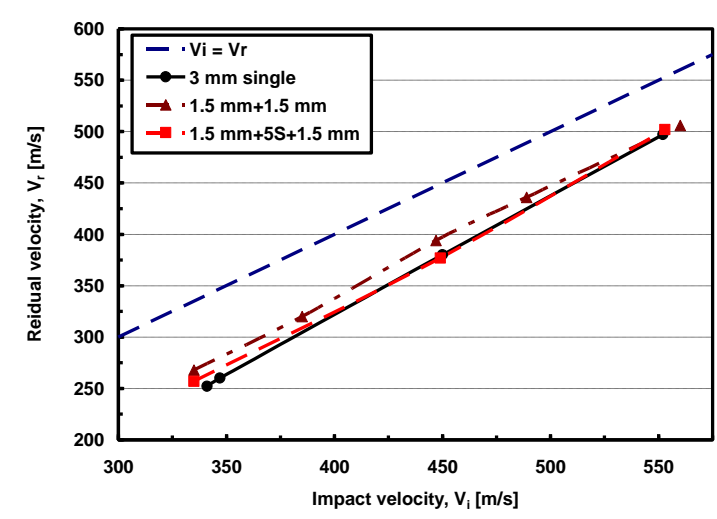

Fig. 4. Change of residual velocity with impact velocity for single, in-contact and spaced doublelayered steel targets having the same total thickness. 


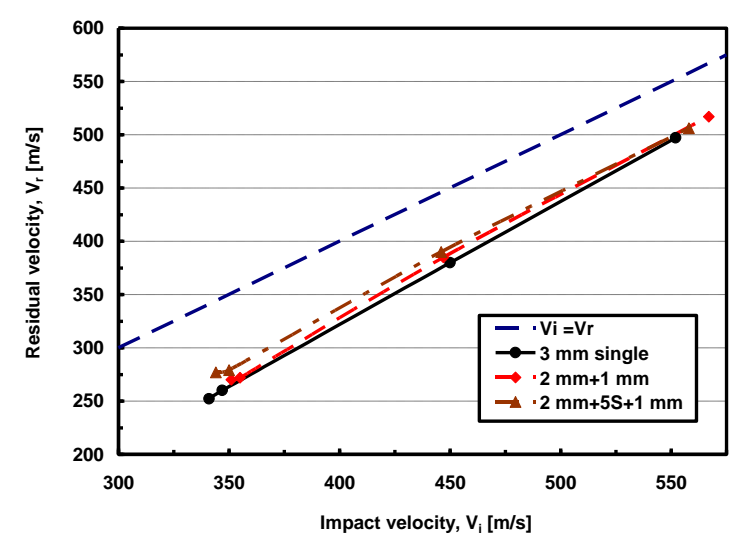

Fig. 5. Change of residual velocity with impact velocity for single, in-contact and spaced double layered targets having the same total thickness.

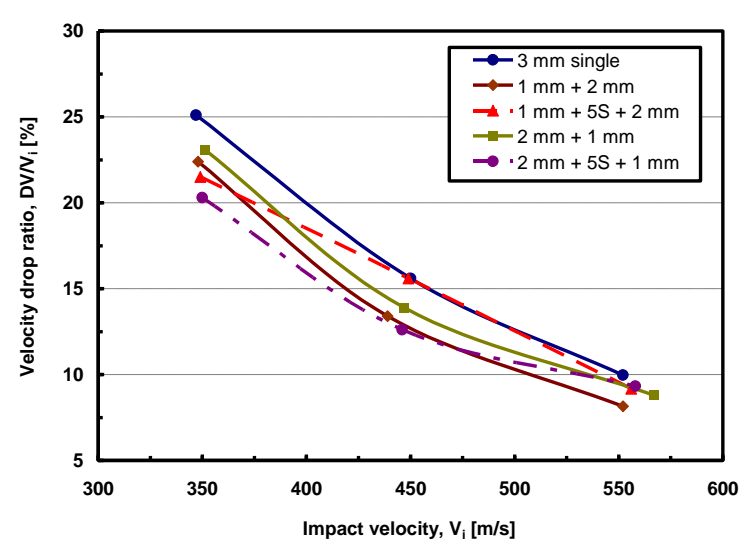

Fig. 7. Change of velocity drop ratio with impact velocity for single, in-contact and spaced double-layered targets having the same total thickness.

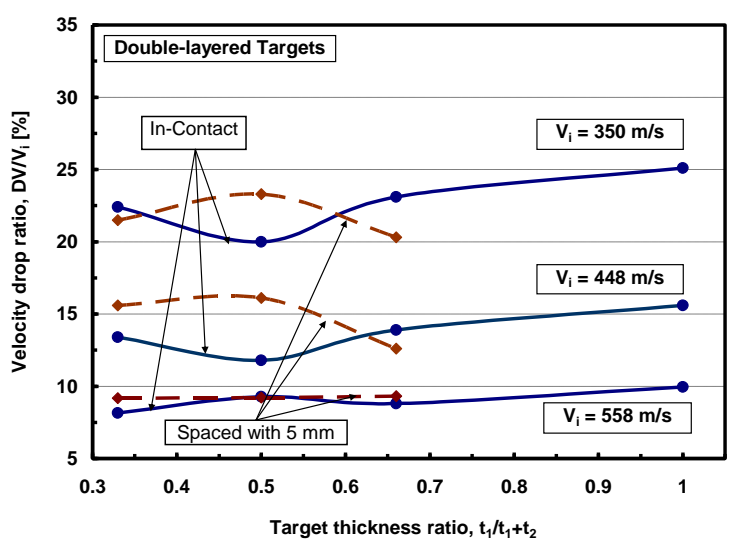

Fig. 9. Change of velocity drop ratio with target thickness ratio for single, in-contact and spaced double-layered targets having the same total thickness at different impact velocities.

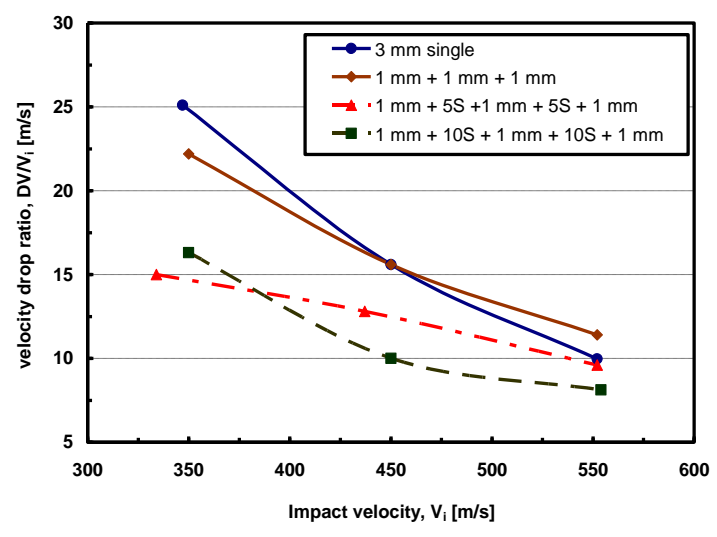

Fig. 6. Change of velocity drop ratio with impact velocity for single, in-contact and spaced triple-layered targets having the same total thickness.

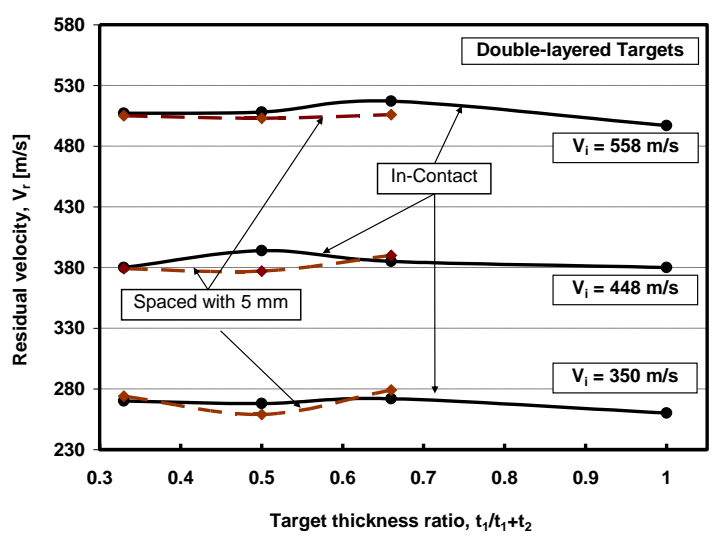

Fig. 8. Change of residual velocity with target thickness ratio for single, in-contact and spaced doublelayered targets having the same total thickness at different impact velocities.

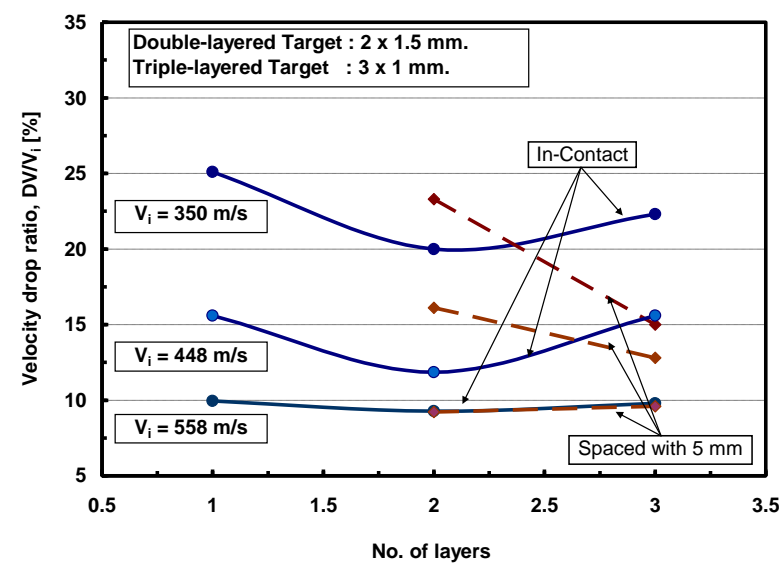

Fig. 10. Change of velocity drop ratio with no. of target layers for single, in-contact and spaced double and triple-layered targets having the same total thickness at different impact velocities. 


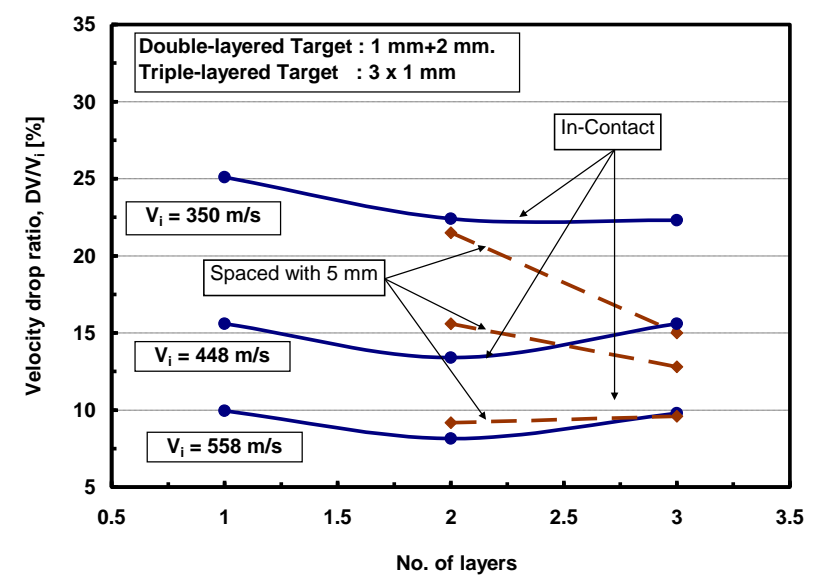

Fig. 11. Change of velocity drop ratio with no. of target layers for single, in-contact and spaced double and triple-layered targets having the same total thickness at different impact velocities.

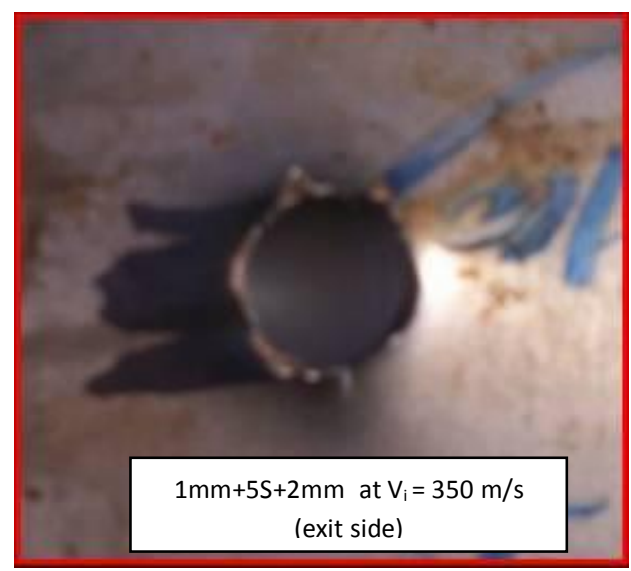

Fig. 13. A picture showing the no. of petals and shapes due to the impact of double-layered target having $5 \mathrm{~mm}$ space in between with $V_{i}=350 \mathrm{~m} / \mathrm{s}$.

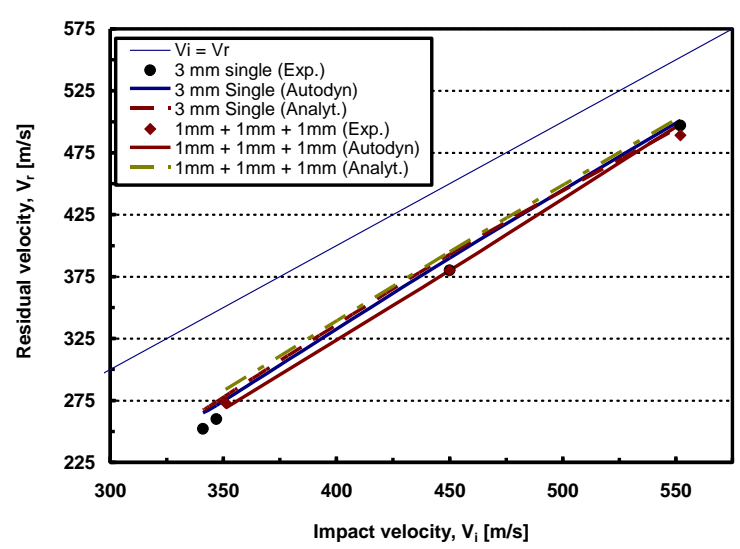

Fig. 15. Comparison between predictions of Autodyn-2D and analytical model of Ref. [1], respectively, with experi. measurements due to the change of residual velocity with impact velocity for single and in-contact triple-layered targets.

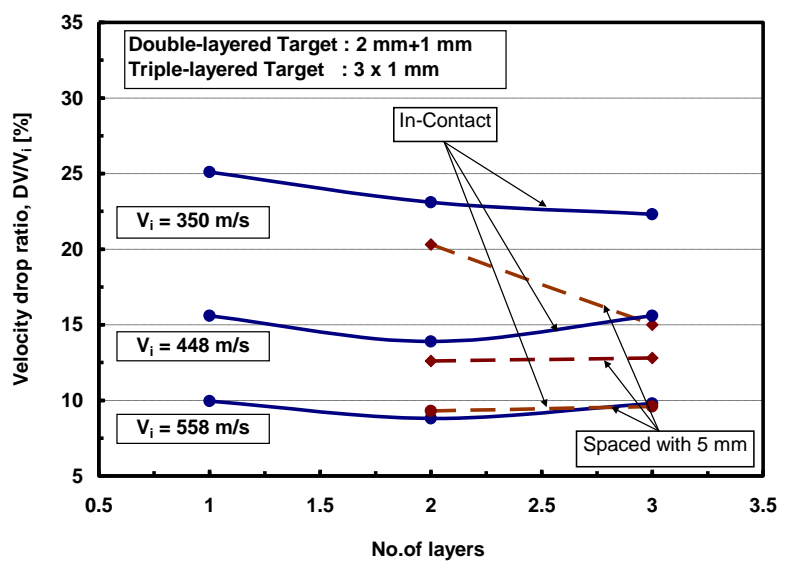

Fig. 12. Change of velocity drop ratio with no. of target layers for single, in-contact and spaced double and triple-layered targets having the same total thickness at different impact velocities.

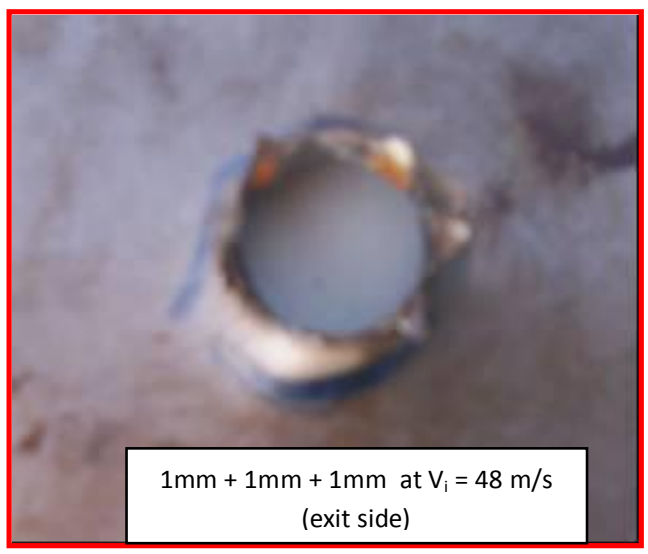

Fig. 14. A picture showing the petalling failure mode of the back plate of a triple-layered target, incontact, at $V_{i}=448 \mathrm{~m} / \mathrm{s}$.

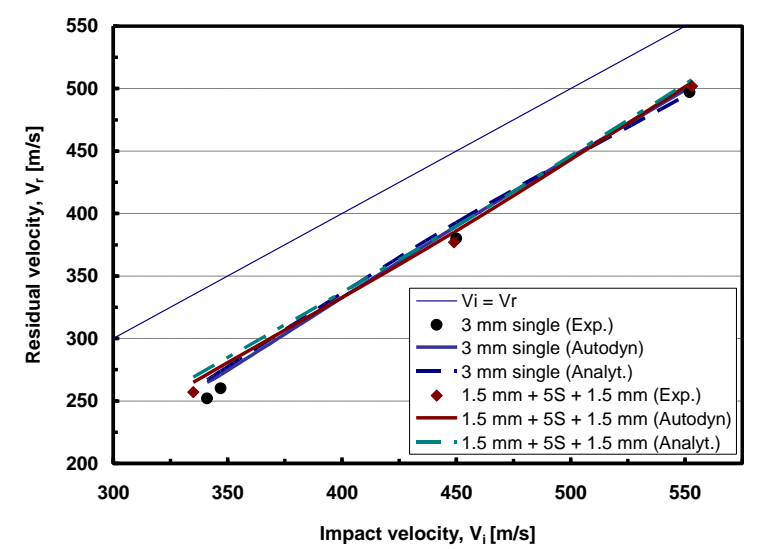

Fig. 16. Comparison between predictions of Autodyn2D and analytical model of Ref. [1], respectively, with experi. measurements due to the change of residual velocity with impact velocity for single and spaced double-layered targets. 